\title{
Isso foi compartilhado com sucesso: questões de consumo midiático dos jovens paulistanos no Facebook ${ }^{1}$.
}

\author{
This was shared with success: questions of media consumption \\ of young people from São Paulo on Facebook.

\section{Esto fue compartido con el éxito: cuestiones sobre el consumo mediático de jóvenes de São Paulo en Facebook.}

\author{
M. Cristina Dias Alves ${ }^{2}$ \\ Eneus Trindade ${ }^{3}$ \\ Livia Silva de Souza ${ }^{4}$ \\ Rosana Mauro 5 \\ Cinira Baader ${ }^{6}$
}

\begin{abstract}
Resumo
A Rede Brasil Conectado desenvolve estudos sobre as práticas dos jovens brasileiros na internet, com a colaboração de equipes de pesquisadores de universidades de todo o país ${ }^{7}$. A fase exploratória da pesquisa "Jovem e consumo midiático em tempos de convergência", da qual participamos, nos forneceu alguns dados que desencadearam reflexões sobre os sentidos emergentes da trajetória dos jovens paulistanos na rede social Facebook. Neste texto, especificamente, nos atemos aos dados dos perfis e aos supertemas recorrentes nos posts dos jovens observados para inferir sobre usos e consumos midiáticos nessa rede social e, inclusive, como o Facebook participa na manutenção ou na transformação das culturas na lógica das sociedades midiatizadas.
\end{abstract}

Palavras-Chave: Jovens. Internet. Facebook. São Paulo. Consumo midiático.

\footnotetext{
1 Trabalho similar foi apresentado no GP América Latina, Mídia, Culturas e Tecnologias Digitais do XVII Encontro dos Grupos de Pesquisa em Comunicação, evento componente do $40^{\circ}$ Congresso Brasileiro de Ciências da Comunicação.

2 Doutora em Ciências da Comunicação pelo PPGCOM ECA/USP, mestre em Comunicação e Práticas de Consumo pela ESPM/SP. Pesquisadora da equipe São Paulo da Rede Brasil Conectado. Integrante do Grupo de Estudos Semióticos em Comunicação, Cultura e Consumo, GESC3, CNPq. E-mail: crisdays@ gmail.com.

3 Professor Livre Docente da ECA/USP do Curso de Publicidade e Propaganda e do PPGCOM/USP. Coordenador da equipe São Paulo da Rede Brasil Conectado. Více-líder do Grupo de Estudos Semióticos em Comunicação, Cultura e Consumo, GESC, CNPq. E-mail: eneustrindade@usp.br.

${ }^{4}$ Doutora e mestre em Ciências da Comunicação pelo PPGCOM ECA/USP. Pesquisadora da equipe São Paulo da Rede Brasil Conectado. Integrante do Grupo de Estudos Semióticos em Comunicação, Cultura e Consumo, GESC3, CNPq. E-mail: livia.2s@gmail.com.

${ }^{5}$ Doutoranda e mestre em Ciências da Comunicação no PPGCOM ECA/USP. Pesquisadora da equipe São Paulo da Rede Brasil Conectado. E-mail: mauro.rosana@gmail.com.

${ }^{6}$ Doutoranda e mestre em Ciências da Comunicação no PPGCOM ECA/USP. Pesquisadora da equipe São Paulo da Rede Brasil Conectado. Integrante do Grupo de Estudos Semióticos em Comunicação, Cultura e Consumo, GESC3, CNPq. E-mail: c.baader@usp.br

${ }^{7}$ Participam da Rede Brasil Conectado 27 equipes/estados, mais o Distrito Federal, sob a coordenação da Profa. Dra. Nilda Jacks e vice-coordenação da Profa. Dra. Mariângela Toaldo, ambas da UFRGS. A partir do relatório da equipe São Paulo, elaboramos as reflexões apresentadas neste texto, relatório em que parte da estruturação dos dados contou com a colaboração das pesquisadoras Maria Clara Sidou Monteiro, Fernanda Chocron Miranda e Paula Coruja, respectivamente doutorandas e mestra pelo PPGCOM UFRGS.
} 


\begin{abstract}
The Rede Brasil Conectado have developing studies about young Brazilians practices on the internet with the teams of researchers from universities all over the country. The exploratory phase of research "Young's media consumption in convergence times", in which we participated, provided us some data that triggered reflections on the emerging meanings of the trajectory of young people from São Paulo on the Facebook. In this text, we specifically observe the profile data and the recurrent super-themes in the young's posts observed to infer media usage and consumption in this social network, and even, how Facebook participates in the maintenance or transformation of cultures in the logic of societies mediatized.
\end{abstract}

Keywords: Young. Internet. Facebook. São Paulo. Media consumption.

\title{
Resumen
}

La Rede Brasil Conectado desarrolla estudios sobre las prácticas de los jóvenes brasileños en Internet con la colaboración de equipos de investigadores de universidades de todo el país. La fase exploratoria de la investigación "Joven y consumo mediático en tiempos de convergencia", de la cual participamos, nos proporcionó algunos datos que desencadenaron reflexiones sobre los sentidos emergentes de la trayectoria de los jóvenes paulistanos en la red social Facebook. En este texto, nos atemos, específicamente, a los datos de los perfiles ya los súper temas recurrentes en los mensajes de los jóvenes observados para inferir sobre usos y consumos mediáticos en esta red social e incluso como Facebook participa en el mantenimiento o la transformación de las culturas en la lógica de las sociedades de los medios de comunicación.

Palabras clave: Jóvenes. Internet. Facebook. São Paulo. Consumo mediático.

\section{INTRODUÇÃO}

articipar da Rede Brasil Conectado e, especificamente, desta fase da pesquisa $\mathrm{P}$ sobre o consumo midiático dos jovens paulistanos na rede social Facebook, abriu-nos a possibilidade de inferir sobre os dados observados, armazenados e categorizados por meio do software $N$ Vivo $^{8}$ e as possíveis lógicas dos usos e consumos dos jovens na rede, como um caminho à reflexão e à aproximação de conceitos.

Durante sete dias consecutivos (entre 10 e 16 de março de 2013), após a anuência em participar da pesquisa, dez jovens com idade entre 18 e 24 anos ( 5 de cada gênero ${ }^{9}$ ) foram observados na rede social. A identificação desses jovens seguiu um protocolo detalhado,

\footnotetext{
${ }^{8}$ Esta versão do programa $Q S R N U D * I S T$ possibilita reunir diferentes arquivos (textos, fotografias e vídeos) em um só projeto, além da organização e análise de informações não estruturadas.

${ }^{9}$ A categoria gênero foi definida pela própria plataforma, que permite ao usuário escolher uma identidade de gênero (desde fevereiro de 2015: masculino, feminino, transgênero, assexuado ou mesmo um objeto) e quem pode ou não visualizar esse item, similar às permissões das informações pessoais (localidade, emprego ou formação acadêmica).
}

Comun. \& Inf., Goiânia, GO, v. 21, n. 1, p. 109-125, jan./mai. 2018 
comum às equipes de todo o país, que incluía a criação de um perfil para o monitoramento e solicitação de amizade ${ }^{10}$.

A coleta foi dividida em três partes: dados pessoais do perfil (onde estudou, trabalhou e morou; religião e status de relacionamento); conteúdo curtido (livros, música, filmes, programas de TV, times, aplicativos etc.) e, enfim, as postagens ${ }^{11}$ realizadas. Apesar de o conteúdo dos posts ser o dado principal, coletamos outras informações, como comentários, quantidade de curtidas e de compartilhamentos.

No caso da análise do perfil, consideramos cinco aspectos: "sobre" (breve descrição de si mesmo); "citações favoritas" (poesias, frases e letras de música); "histórico" (datas consideradas importantes); "estudo" (universidades/faculdades e escolas, atuais e anteriores); "trabalho" (atuais, anteriores e empregadores) e, ainda, o item "favoritos", com informações das fanpages curtidas no período a partir da classificação estabelecida pela própria rede social, localizada na página de cada usuário, em 19 temáticas ${ }^{12}$ : aplicativos, atividades, atletas, esportes, eventos, filmes, grupos, inspirações, interesses, jogos, livros, música, outros, pessoas que lhe inspiram, restaurantes, roupas, sites, time e TV.

Em relação ao item posts/postagens, devido à abrangência da classificação ${ }^{13}$, realizamos um recorte com base na evidência de assuntos, considerando a proposição de Jensen (1997) quanto àqueles mais importantes para os sujeitos ao entrar em contato com algum referente midiático, pois estão "articulados en un proceso de inferencia, interpretación o semiosis que hace corresponder las categorías de la experiencia cotidiana con las categorías de los discursos de los medios de comunicación” (JENSEN, 1997, p.185).

\footnotetext{
${ }^{10}$ A partir da autorização de observação, cada equipe criou um formulário de triagem on-line com os dados necessários (link do perfil no Facebook, cidade/estado de nascimento, idade, escolaridade e renda familiar) identificada como pertencentes ao grupo a ser estudado. O link desse questionário foi divulgado em fanpages e grupos no Facebook com clara vinculação ao contexto estadual, um número satisfatório de membros e de interações entre eles. O link também foi compartilhado nos perfis pessoais dos integrantes da Rede, enviado por e-mail para os contatos dos pesquisadores e divulgado na imprensa e em portais institucionais

${ }^{11}$ Cada postagem foi copiada e colada no programa Word, nomeada pelo nome do perfil e número de postagem. Se houvesse link para outros sites, esse deveria ser copiado e colado logo abaixo do post coletado. No caso de link para vídeos foi solicitada a realização do download do conteúdo sempre que possível.

${ }^{12}$ A pesquisa leva em conta as temáticas do período de monitoramento uma vez que a classificação do Facebook foi atualizada e ampliada após a nossa observação.

${ }^{13}$ Classificações das postagens: a) tipo de post: automático, autoral, compartilhado, tag (post de amigos na timeline do jovem), entre outros; b) dispositivo utilizado: de que plataforma a postagem foi enviada; c) temas: assunto das postagens; d) check-in: registros/compartilhamentos da localização no momento da postagem (a partir da seleção de locais previamente cadastrados no Facebook); e) atualização do perfil e local: alterações da foto, do status de relacionamento, de trabalho etc.; f) canal de comunicação: uso para envio de mensagens, semelhante ao e-mail; g) marcações: links de algum perfil do Facebook (membros da família, amigos e conhecidos etc.) diretamente no texto da postagem; h) redes sociais e aplicativos: divulgação, referência e busca de outras redes e aplicativos (exemplo ASK.fm); i) não classificáveis: posts que não se enquadravam em nenhum tema ou tipo de postagem e, portanto, não foram analisados.
}

Comun. \& Inf., Goiânia, GO, v. 21, n. 1, p. 109-125, jan./mai. 2018 
Desse modo, das 34 temáticas categorizadas inicialmente ${ }^{14}$, selecionamos 11 assuntos recorrentes em todos os estados e que denominamos "supertemas": cotidiano, esporte, evento, filosofia ordinária, humor, mídia, música, publicidade/institucionais, questões sociais, religião/espiritualidade e vida estudantil. Ressaltamos o cuidado no protocolo de pesquisa de todas as equipes quanto à forma de armazenamento de dados para viabilizar a análise no programa NVivo em arquivos com extensão doc, um dos formatos aceitos pelo software ${ }^{15}$.

O objetivo do levantamento foi a exploração de elementos que subsidiem hipóteses ou pressupostos sobre as lógicas dos usos e consumos midiáticos desses jovens no Facebook. Sabemos que a metodologia suscita fragilidades, mas a arquitetura exploratória mostra-se rentável e a inferência sobre os dados, ainda que não generalizável, permite propor conceitos da dimensão dos usos midiáticos dos jovens.

Desse modo, o descritivo apresentado a seguir presta-se ao olhar teórico do consumo cultural midiático, como se referem Toaldo e Jacks (2013) e considera aspectos dos sujeitos com suas mediações culturais manifestadas em lógicas midiatizadas ou mediações comunicacionais (TRINDADE; PEREZ, 2016).

\section{OS PERFIS DOS JOVENS}

Os itens observados no perfil resultaram em 29 referências (quadro 1): 8 para "estudo", 8 para "trabalho", 8 para "histórico", 3 para "sobre" e 2 para "citações favoritas", além do preenchimento do item "gênero".

Quadro 1 - Ocorrência do preenchimento do perfil

\footnotetext{
${ }^{14}$ São elas: acontecimentos; afetos/emoções e sentimentos; animais/pets; artes plásticas/eletrônicas e digitais; performance; astrologia; autoajuda; cinema; comportamento; cotidiano; datas comemorativas; esporte; evento; filosofia ordinária; fotografia; games; gastronomia; hoax; humor; indiretas; lembranças/memórias; literatura; mídia; moda; música; polícia; política; publicidade/institucionais; questões sociais; reclamações; religião/espiritualidade; saúde/qualidade de vida; self; sustentabilidade; teatro; tecnologia; testes; trivialidades; viagem; vida estudantil e vida profissional.

15 A versão atual do software $\left(\mathrm{n}^{\circ} 10\right)$ permite a varredura de dados diretamente em páginas na internet, bem como em redes sociais, incluindo o Facebook. Entretanto, no período de observação, a equipe coordenadora dava início ao uso do programa, ainda sem o domínio total das potencialidades.
}

Comun. \& Inf., Goiânia, GO, v. 21, n. 1, p. 109-125, jan./mai. 2018 


\begin{tabular}{|c|c|c|c|c|c|c|c|}
\hline $\begin{array}{c}\text { N. de } \\
\text { jovens }\end{array}$ & $\begin{array}{c}\text { Perfil: } \\
\text { gênero = feminino }\end{array}$ & $\begin{array}{c}\text { Perfil: } \\
\text { gênero }=\text { masculino }\end{array}$ & $\begin{array}{c}\text { Citações } \\
\text { favoritas }\end{array}$ & Estudo & Histórico & Sobre & Trabalho \\
\hline 1 & Não & Sim & Não & Sim & Sim & Não & Sim \\
\hline 2 & Sim & Não & Não & Sim & Sim & Não & Sim \\
\hline 3 & Sim & Não & Não & Sim & Sim & Não & Sim \\
\hline 4 & Sim & Não & Não & Sim & Sim & Sim & Sim \\
\hline 5 & Sim & Não & Não & Sim & Sim & Não & Não \\
\hline 6 & Não & Sim & Sim & Não & Sim & Sim & Sim \\
\hline 7 & Não & Sim & Não & Não & Não & Não & Sim \\
\hline 8 & Não & Sim & Sim & Sim & Sim & Não & Sim \\
\hline 9 & Não & Sim & Não & Sim & Sim & Sim & Sim \\
\hline 10 & Sim & Não & Sim & Não & Não & Não \\
\hline
\end{tabular}

Fonte: Elaborado pela equipe da Rede Brasil Conectado

Percebemos que nenhum dos itens analisados foi preenchido completamente e, dentre os 3 mais relevantes, "estudo" obteve mais adesão, preenchido por 8 jovens, totalizando 81 palavras diferentes ${ }^{16}$. As de maior ocorrência se referem à localidade das instituições de ensino atuais e anteriores e ao grau de escolaridade. A repetição da palavra "universidade" (5) remete ao local das instituições, junto dos anos de conclusão do ensino médio e de início da faculdade (grau de escolaridade). Há também os que sinalizaram o tipo de curso superior ou técnico/ensino médio, atual ou anterior.

Junto de "estudo", o item "trabalho" obteve a adesão de 8 jovens, num total de 79 palavras diferentes, sendo "localização" a de maior incidência - "São" (7), "Paulo" (7) - além da palavra "empregadores" (4). Observamos que esses jovens sinalizaram o início/fim de um trabalho, já que foi comum a recorrência de datas. Notamos que houve diversidade de áreas e posições profissionais, de estagiário a assistente, de baterista a servidor público, entre outras, devido à incidência de palavras específicas.

Também 8 jovens preencheram "histórico", item no qual poderiam indicar as datas e os eventos significativos e que resultou 83 palavras diferentes, sinalizando o começo ou o fim de ciclos. A palavra "instituição", destaque com 22 ocorrências, descreve o local dos acontecimentos, seja pela aprovação no vestibular ou início de um novo trabalho. Outros eventos importantes estiveram pulverizados em ocorrência única, além da identificação de pessoas.

Apesar de negligenciadas, as 2 ocorrências em "citações favoritas" resultaram 42 palavras diferentes, a grande maioria (37) com ocorrência única, indicação de frases isoladas. Houve referências à cultura pop (na frase I'm your father, do filme Star Wars V) ou relativas a Albert Einstein, pela ocorrência única das palavras que formam esse nome. As demais frases

16 Devido à prioridade das discussões, além do pouco espaço, as nuvens de palavras geradas pelo software NVivo, a partir dos dados coletados, constam apenas das análises regional e nacional.

Comun. \& Inf., Goiânia, GO, v. 21, n. 1, p. 109-125, jan./mai. 2018 
versaram sobre temas do cotidiano, com 1 ou 2 ocorrências, e também palavras em inglês da área de programação.

Ao todo, 3 jovens preencheram o item "sobre" utilizando frases para falar de si, evidenciando uma recorrência considerável do idioma inglês: 36 das 50 palavras foram nesse idioma, com pouquíssimas repetições. "Demolay”, destaque entre as demais, refere-se à “Ordem Demolay", organização paramaçônica destinada a jovens do gênero masculino e citada por apenas 1 jovem ( 3 repetições) e se configura um caso isolado da amostra.

Com base na recorrência das palavras geradas a partir dos "perfis", constatamos que os jovens paulistanos evitaram preencher itens de cunho autodescritivo (sobre) e, quando sim, utilizaram elementos da cultura pop, frases próprias e lugares comuns (citações favoritas), com atenção às datas e aos verbos que indicam início/fim de ciclos de estudo/trabalho (histórico). A sinalização das instituições de ensino e respectivas localidades (estudo) foram complementadas com indicação do grau ou tipo de formação, superior/ensino médio/técnico, atual ou anterior, com ocorrência similar no item "trabalho".

Esse processo de quantificação incitou o seguinte questionamento: seria possível extrair dados com alguma possibilidade de generalização sobre esses perfis, a partir das mediações culturais reveladas em práticas midiatizadas pelo/no Facebook, com expressões das mediações comunicacionais da cultura daquele ambiente midiático de interação? Acreditamos que sim, caso a amostra fosse maior, com captura a partir de dados brutos colhidos em Excel, para posterior transferência e processamento por meio do software NVivo, considerando categorias subjetivas de coleta que permitissem acessar aspectos expressivos dessa subjetividade apresentada na mediação comunicacional do Facebook para o grupo estudado. Entretanto, no estudo exploratório realizado, os resultados mostraram apenas alguns indícios das possibilidades de compreensão dessas lógicas de subjetividade midiatizadas.

\section{OS FAVORITOS E OS SUPERTEMAS}

Entre os 19 temas disponíveis no Facebook, 14 favoritos foram identificados (gráfico 1): aplicativos, atividades, atletas, esportes, filmes, grupos, inspirações, interesses, jogos, livros, música, outros, time e TV, dentre os quais se destacaram música e outros (10 perfis cada), seguidos por filmes e TV (9 perfis). É importante demarcar, mais uma vez, que essas quantificações não se prestam a generalizações, mas à identificação de inferências possíveis sobre as lógicas de usos e consumos midiáticos do grupo observado. 
A primeira lógica que percebemos é que o Facebook, nos usos e consumos do grupo investigado, apresenta-se como uma metamídia, resultado do fenômeno da convergência midiática/tecnológica. Pela plataforma circulam e são discutidos formatos e conteúdos de outros meios/mídias, ou seja, uma metamídia com função de reverberação e que apresenta as mediações culturais na expressão de mediações comunicacionais da cultura, como escreve Martín-Barbero (2004), cuja dinâmica da circulação pode racionalizar uma lógica midiática de consumo presente na vida dos sujeitos observados.

Gráfico 1 - Número absoluto de perfis que apresentaram “favoritos” preenchidos

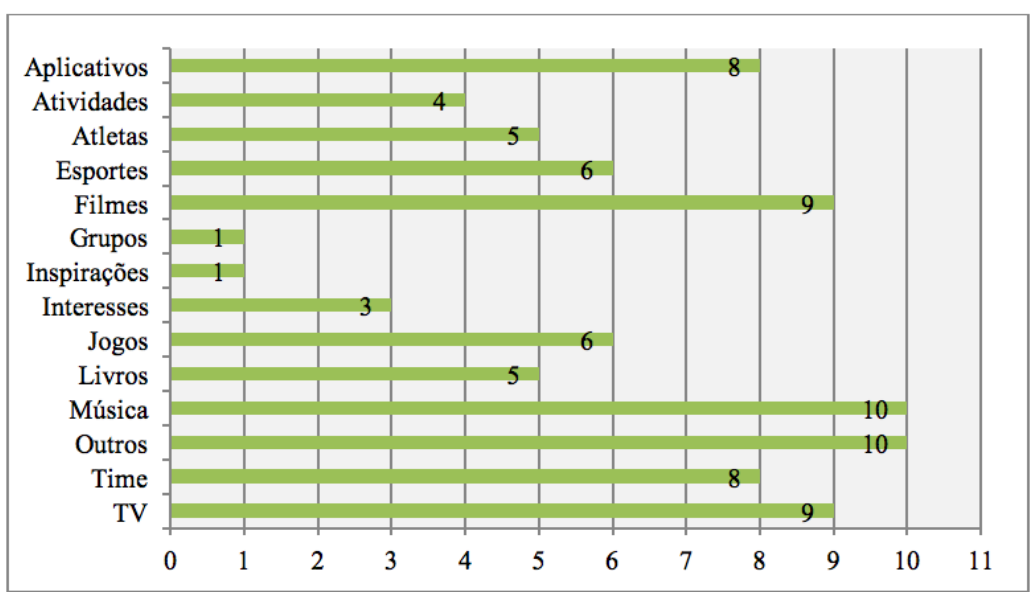

Fonte: Elaborado pela equipe da Rede Brasil Conectado

$\mathrm{Na}$ distribuição dos favoritos no perfil ${ }^{17}$ (quadro 2), observamos que 7 jovens preencheram 8 ou mais temáticas, sendo que 2 deles (gêneros feminino e masculino) curtiram 12 dos 14 temas e apenas 1 jovem (gênero feminino) registrou menos informações, com 5 itens (grupo, interesses, música, outros e TV).

Quadro 2 - Distribuição de temas favoritos nos perfis observados.

\begin{tabular}{|l|c|c|c|c|c|c|c|c|c|c|c|c|c|c|c|c|}
\hline N & Sexo & Aplicativas & Atividades & Atletas & Esportes & Filmes & Gnpos & Inspirações & Interesses & Jogos & Livros & Mísica & Outros & Time & TV & TOTAL \\
\hline $\mathbf{1}$ & $\mathrm{M}$ & 1 & 0 & 1 & 1 & 1 & 0 & 0 & 0 & 1 & 0 & 1 & 1 & 1 & 1 & $\mathbf{9}$ \\
\hline $\mathbf{2}$ & $\mathrm{F}$ & 1 & 1 & 1 & 1 & 1 & 0 & 0 & 1 & 1 & 1 & 1 & 1 & 1 & 1 & $\mathbf{1 2}$ \\
\hline $\mathbf{3}$ & $\mathrm{F}$ & 1 & 0 & 0 & 1 & 1 & 0 & 0 & 0 & 0 & 0 & 1 & 1 & 1 & 0 & $\mathbf{6}$ \\
\hline $\mathbf{4}$ & $\mathrm{F}$ & 1 & 0 & 1 & 0 & 1 & 0 & 0 & 0 & 1 & 0 & 1 & 1 & 1 & 1 & $\mathbf{8}$ \\
\hline $\mathbf{5}$ & $\mathrm{F}$ & 0 & 0 & 0 & 0 & 0 & 1 & 0 & 1 & 0 & 0 & 1 & 1 & 0 & 1 & $\mathbf{5}$ \\
\hline $\mathbf{6}$ & $\mathrm{M}$ & 1 & 1 & 1 & 1 & 1 & 0 & 0 & 1 & 1 & 1 & 1 & 1 & 1 & 1 & $\mathbf{1 2}$ \\
\hline $\mathbf{7}$ & $\mathrm{M}$ & 1 & 1 & 1 & 1 & 1 & 0 & 0 & 0 & 1 & 0 & 1 & 1 & 1 & 1 & $\mathbf{1 0}$ \\
\hline $\mathbf{8}$ & $\mathrm{M}$ & 0 & 1 & 0 & 1 & 1 & 0 & 0 & 0 & 1 & 1 & 1 & 1 & 1 & 1 & $\mathbf{9}$ \\
\hline $\mathbf{9}$ & $\mathrm{M}$ & 1 & 0 & 0 & 0 & 1 & 0 & 0 & 0 & 0 & 1 & 1 & 1 & 0 & 1 & $\mathbf{6}$ \\
\hline $\mathbf{1 0}$ & $\mathrm{F}$ & 1 & 0 & 0 & 0 & 1 & 0 & 1 & 0 & 0 & 1 & 1 & 1 & 1 & 1 & $\mathbf{8}$ \\
\hline TOTAL & $\mathbf{8}$ & $\mathbf{4}$ & $\mathbf{5}$ & $\mathbf{6}$ & $\mathbf{9}$ & $\mathbf{1}$ & $\mathbf{1}$ & $\mathbf{3}$ & $\mathbf{6}$ & $\mathbf{5}$ & $\mathbf{1 0}$ & $\mathbf{1 0}$ & $\mathbf{8}$ & $\mathbf{9}$ & \\
\hline
\end{tabular}

Fonte: Elaborado pela equipe da Rede Brasil Conectado

Como escrevemos, a análise dos "favoritos" foi realizada com o uso do software

\footnotetext{
${ }^{17}$ Durante a análise recorremos à frequência de palavras, além de checar os termos que apareceram nas nuvens diretamente nas fontes (arquivos-texto com informações do perfil de cada jovem observado).
}

Comun. \& Inf., Goiânia, GO, v. 21, n. 1, p. 109-125, jan./mai. 2018 


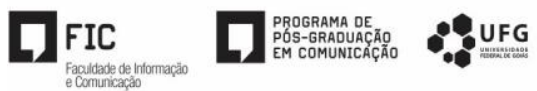

NVivo para composição de nuvens de palavras mais relevantes em cada categoria. Nesse texto, apresentamos apenas a síntese da observação (nos quadros anteriores) na qual destacamos o fato de que as categorias "música, outros, filmes e TV" foram as mais preenchidas entre os 14 temas mencionados pelos jovens. De modo geral, o grupo observado mostrou-se bastante heterogêneo quanto a hábitos de consumo de mídia e, na categoria “outros", ressaltamos a presença de temas relativos ao Brasil, ao estado/cidade de São Paulo e ao universo do trabalho (comunicação, design) e do lazer (bares, festas e clubes).

A categoria "música" mostrou a preferência por artistas internacionais da cena pop rock, com destaque para Lady Gaga, Amy Winehouse (4 e 3 perfis) e Rita Lee (3 perfis). Em "filmes", o interesse recaiu sobre os gêneros ação e aventura, enquanto na categoria TV, séries e programas de humor.

A partir das preferências sinalizadas nessas categorias percebemos outras lógicas: a primeira diz respeito à mediação cultural do contexto/local, elemento significativo do sentido de pertinência e pertencimento das e nas interações frente ao contexto em que os sujeitos investigados se inserem. A segunda refere-se aos signos midiatizados da juventude que permitem a identificação de "mundos midiatizados" (HEPP, 2014), isto é, universos de imaginários constituídos pelo consumo das mídias. Os resultados evidenciaram o que prevalecia como evidência da circulação no momento da pesquisa.

Entre os diferentes temas das postagens dos jovens de todo o país selecionamos os supertemas considerados mais evidentes na categorização dos 2944 posts coletados pelas 27 equipes. Os jovens de São Paulo publicaram 183 posts (tabela 1), sendo o supertema "cotidiano" o mais recorrente (46 posts), seguido de "música" (39) e "fillosofia ordinária" (27). Já "publicidade/institucionais" foi o supertema com menor relevância (1 postagem) referente a um anúncio de curso preparatório para concurso da Ordem dos Advogados do Brasil $(\mathrm{OAB})$ e cujo gráfico, pela recorrência única, não foi realizado.

Tabela 1 - Distribuição de posts por supertemas 


\begin{tabular}{|l|c|}
\hline Cotidiano & 46 \\
\hline Esporte & 6 \\
\hline Evento & 4 \\
\hline Filosofia ordinária & 27 \\
\hline Humor & 25 \\
\hline Mídia & 12 \\
\hline Música & 39 \\
\hline Publicidade/institucionais & 1 \\
\hline Questões Sociais & 6 \\
\hline Religião/espiritualidade & 10 \\
\hline Vida estudantil & 7 \\
\hline Total & 183 \\
\hline
\end{tabular}

Fonte: Elaborada pela equipe da Rede Brasil Conectado

Desse modo, a partir do levantamento de palavras entre os supertemas categorizados, evidenciamos as mais citadas em cada um deles ${ }^{18}$. No supertema "cotidiano" (gráfico 2), a palavra recorrente foi "café", com 3 citações em postagens sobre o dia a dia dos jovens, como relatos sobre acidentes com copos de café ( 2 vezes) ou habilidade e independência ao preparar a bebida.

Esses resultados nos levam a identificar outra lógica: o Facebook como mídia do eu, fato que se justifica pelo registro de ações do dia a dia, isto é, pela mediação do cotidiano. Nesse sentido, a plataforma deixa de ser metamídia para ganhar um lugar privilegiado da mediação comunicacional da subjetividade dos seus interagentes. Percebemos que essa mediação segue determinadas regularidades, evidenciando uma subjetividade mais ligada à diversão que ao trabalho, mais ao estudo e às situações emocionais difíceis da vida, embora possam ocorrer registros tristes ou disfóricos ao contexto do curtir que não existiam como opção no período investigado ${ }^{19}$.

Gráfico 2 - Frequência de palavras no supertema cotidiano

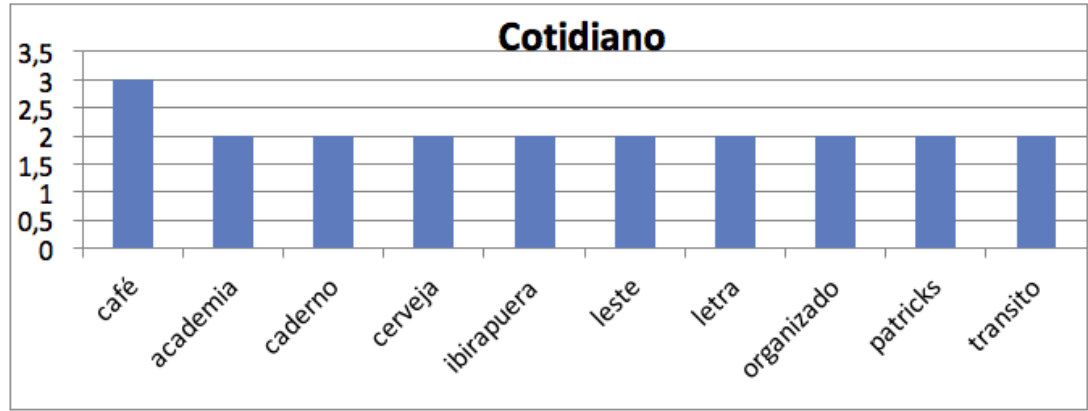

Fonte: Elaborado pela equipe da Rede Brasil Conectado

\footnotetext{
${ }^{18}$ Resultante do software NVivo que não relaciona logicamente os termos, somente a quantificação das palavras. 19 Sobre o acréscimo de botões e as novas opções de reação às postagens ver: "Facebook libera cinco novos botões alternativos ao 'curtir'”. Disponível em: <https://glo.bo/1OuVTBm>. Acesso em: 20 jun. 2017.
}

Comun. \& Inf., Goiânia, GO, v. 21, n. 1, p. 109-125, jan./mai. 2018 
口

Com referência ao supertema "música", o termo Youtube apareceu 21 vezes em posts relacionados a compartilhamentos de música, pela recorrência de extensões de links que direcionam o usuário para o respectivo portal ${ }^{20}$, sejam postagens com trechos ou letras de canções inteiras e mesmo memes com trechos de músicas. Tal registro endossa o caráter metamídia, pelo trânsito de convergência entre plataformas para o consumo cultural de música, e aponta para gramaticalidades complexas resultantes dessas convergências. Para além das intertextualidades são as intermedialidades, como escreve Martín-Barbero (2009, p. 154) "a contaminação entre sonoridades, textualidades, visualidades, as matérias-primas dos gêneros".

Gráfico 3 - Frequência de palavras no supertema música

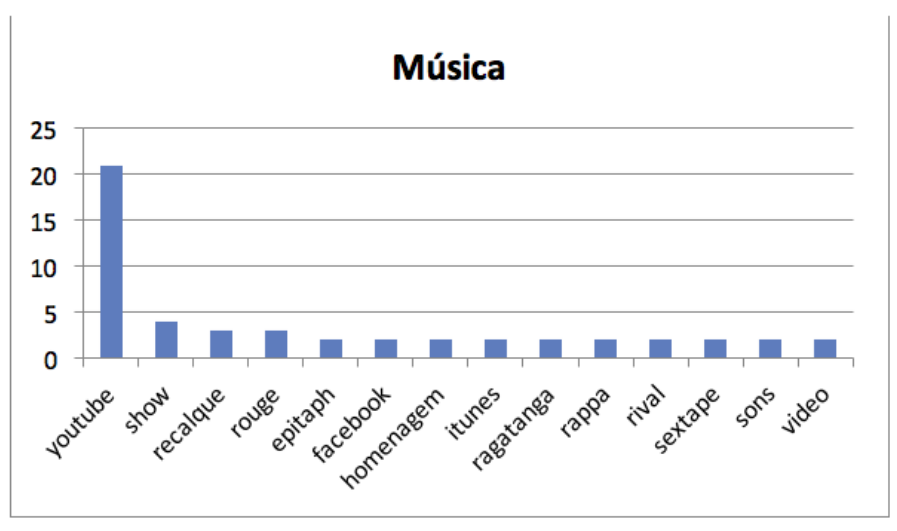

Fonte: Elaborado pela equipe da Rede Brasil Conectado

Com relação ao supertema "filosofia ordinária", foram recorrentes as palavras “amizade", "deus" e "irmã", com 3 repetições cada. "Amizade" apareceu em postagens que ilustram relacionamentos entre usuários, acompanhadas de frases de apoio e compreensão, e “deus" em posts relacionados à experiência e sabedoria, esta última citada 2 vezes. Já "irmã" surgiu em posts compartilhados da página "Minha amiga irmã", cujo conteúdo aborda reflexões sobre a relação entre irmãs que compartilham o sentimento de amizade.

Gráfico 4 - Frequência de palavras no supertema filosofia ordinária

\footnotetext{
${ }^{20}$ Isso porque o NVivo categoriza até os links obtidos da rede social (ver nota anterior).
}

Comun. \& Inf., Goiânia, GO, v. 21, n. 1, p. 109-125, jan./mai. 2018 


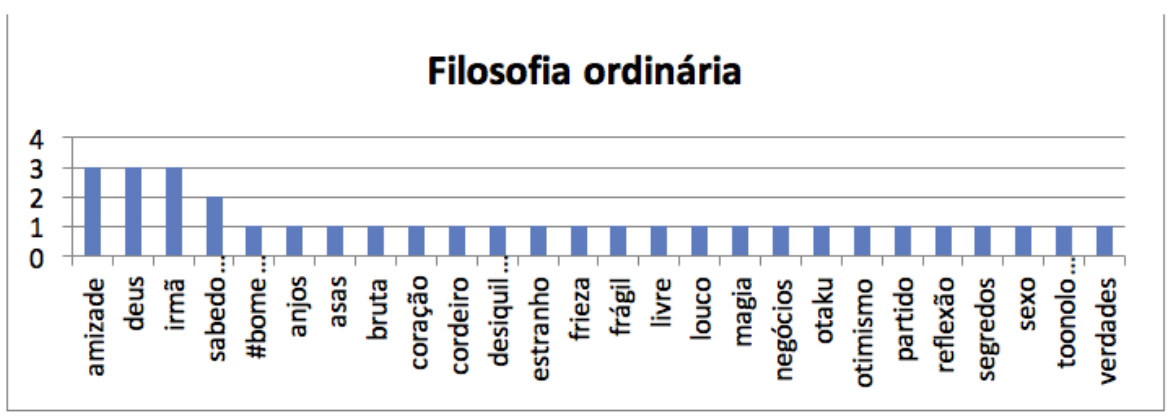

Fonte: Elaborado pela equipe da Rede Brasil Conectado

No supertema "humor", o destaque foram as palavras "Facebook" e "show", citadas 3 vezes. No primeiro caso, a autorreferência pode ser resultado de posts compartilhados na própria rede social. O mesmo acontece com a palavra "show", devido ao compartilhamento da página de humor "Show da humilhação" e, nesse caso, foram repetições da mesma postagem o que sugere uma frequência de palavras não proporcional aos posts a que estão vinculadas.

Gráfico 5 - Frequência de palavras no supertema filosofia ordinária

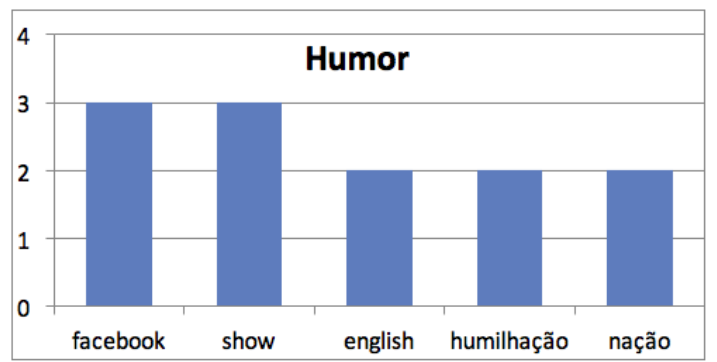

Fonte: Elaborado pela equipe da Rede Brasil Conectado

Como explicita o gráfico 6, a palavra recorrente do supertema "mídia" foi "notícias"21 (6 vezes) e apareceu principalmente em postagens com links do portal UOL Notícias. Um deles remetia à fanpage do UOL no Facebook $^{22}$ e, os demais, ao conteúdo jornalístico publicado no próprio portal, com exceção do post de um artigo opinativo compartilhado por meio da comunidade "Isso é Brasil" da própria plataforma ${ }^{23}$. Observamos que grande parte do conteúdo informativo de jornais e revistas foi compartilhado pelos jovens por meio de páginas e links das próprias plataformas.

Podemos inferir que, além do caráter metamídia do Facebook, o consumo midiático traz o senso comum manifesto no uso da rede social, constituindo o supertema "mídia" metonímia de informação e de jornalismo. Isso sinaliza certo reducionismo na compreensão da

\footnotetext{
${ }^{21} \mathrm{Na}$ soma dos posts, consideramos a escrita da palavra com e sem acento (notícia e noticia).

${ }^{22}$ Disponível em: <https://www.facebook.com/UOLNoticias〉.

${ }^{23}$ Disponível em: <https://www.facebook.com/IssoEBrasil/>.
}

Comun. \& Inf., Goiânia, GO, v. 21, n. 1, p. 109-125, jan./mai. 2018 
complexidade do consumo midiático por parte dos sujeitos observados, que parecem entender as apropriações da mídia como restritas ao consumo de informação de caráter jornalístico.

Gráfico 6 - Frequência de palavras no supertema mídia

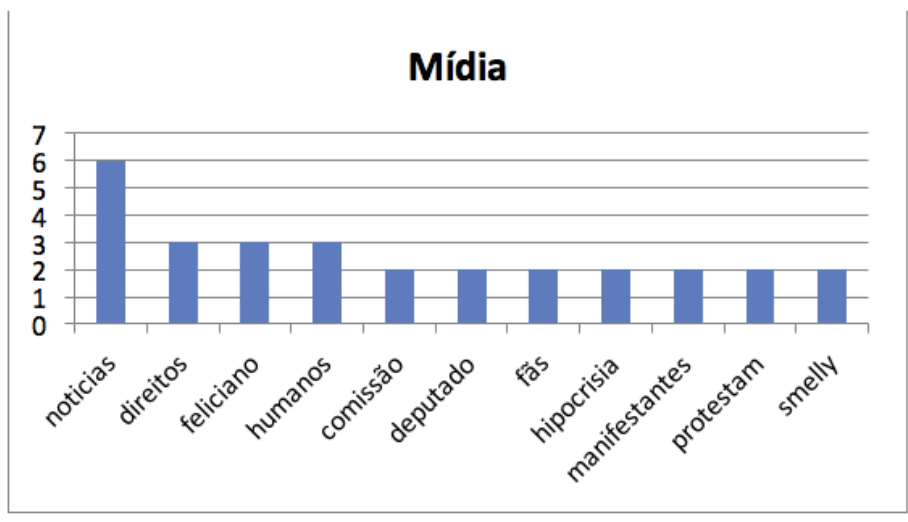

Fonte: Elaborado pela equipe da Rede Brasil Conectado

Em relação ao supertema "religião-espiritualidade", as palavras "bendito" e "papa" foram as únicas repetidas (2 vezes), ambas relacionadas à eleição do novo papa da Igreja Católica Apostólica Romana. A dimensão da mediação cultural da religiosidade também encontrou espaço como mediação comunicacional circulante entre os jovens observados.

Gráfico 7 - Frequência de palavras no supertema religião-espiritualidade

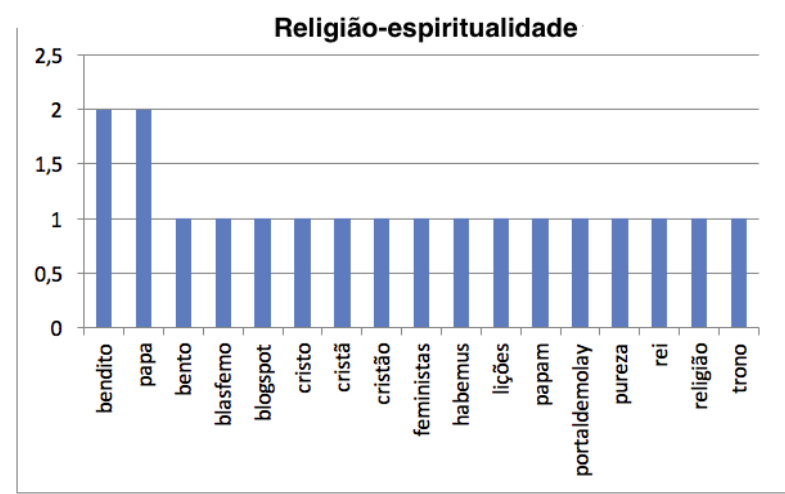

Fonte: Elaborado pela equipe da Rede Brasil Conectado

Ao analisar as postagens referentes ao supertema "vida estudantil", percebemos um equilíbrio na frequência de palavras (1 cada). "Aulas", “depressão", "engenharia", "Faap", "faculdade", "habemus", "swot" apareceram em postagens sobre as práticas de estudo, sendo 2 delas relacionadas à faculdade em curso, bem como "passar" nas avaliações: esforços para estudar (depressão), participar das aulas e conhecer os conteúdos (swot - metodologia para identificação de pontos fortes e fracos) para a formação superior (engenharia); "Faap" (Fundação Armando Alvares Penteado") e "faculdade".

Comun. \& Inf., Goiânia, GO, v. 21, n. 1, p. 109-125, jan./mai. 2018 


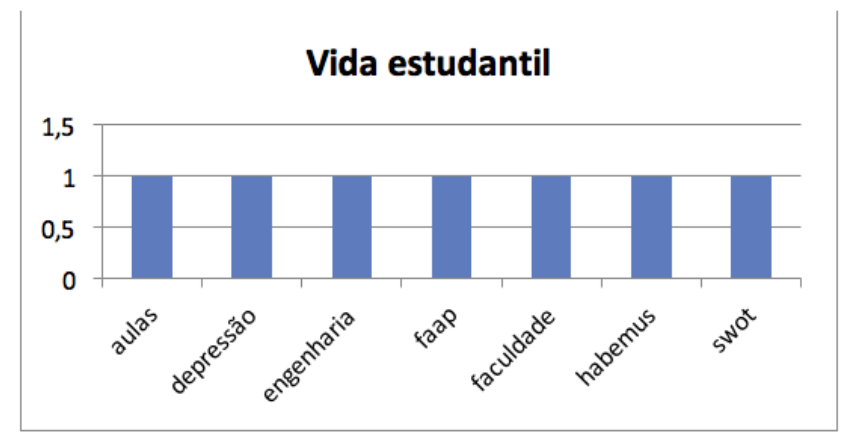

Fonte: Elaborado pela equipe da Rede Brasil Conectado

No que se refere ao supertema "questões sociais", a palavra "ditadura" foi recorrente (3 vezes), só que surgiu na opinião de apenas 1 jovem que questionava a existência de uma ditadura gay e uma ditadura do feminismo. Houve frequência de posicionamentos polarizados nesse supertema, por vezes, posts sobre sexualidade e homofobia foram opostos, como um jovem que defendeu a amplitude dos direitos civis e outro que criticou a imposição da ditadura gay.

Nesse caso, as reverberações decorrentes da função metamídia mostram-se com potencialidade, pelos vestígios em discursos de comentários circulantes, para constituir-se como espaço de debate midiático, podendo ser ampliado para as discussões de gostos de outros usos e consumos que por ventura possam ser colocados em embates nos processos de circulação. 
Gráfico 9 - Frequência de palavras no supertema questões sociais

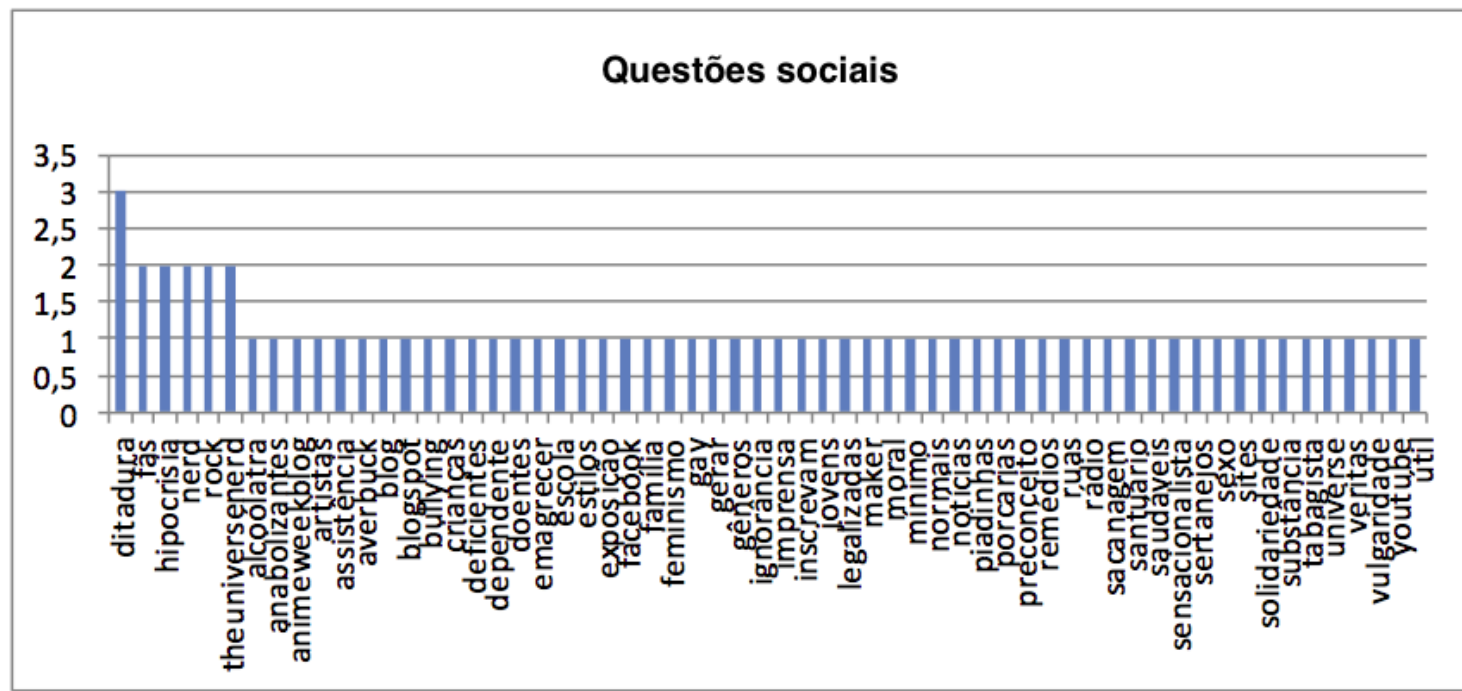

Fonte: Elaborado pela equipe da Rede Brasil Conectado

No supertema "esporte", a palavra "Palmeiras" obteve mais repetições (6 vezes), relacionada a um post de notícia sobre um jogo desse time e outro ao resumo de uma última partida. Consideramos, ainda, a palavra "alviverde", com 5 repetições (remete às cores do Palmeiras).

Gráfico 10 - Frequência de palavras no supertema esporte

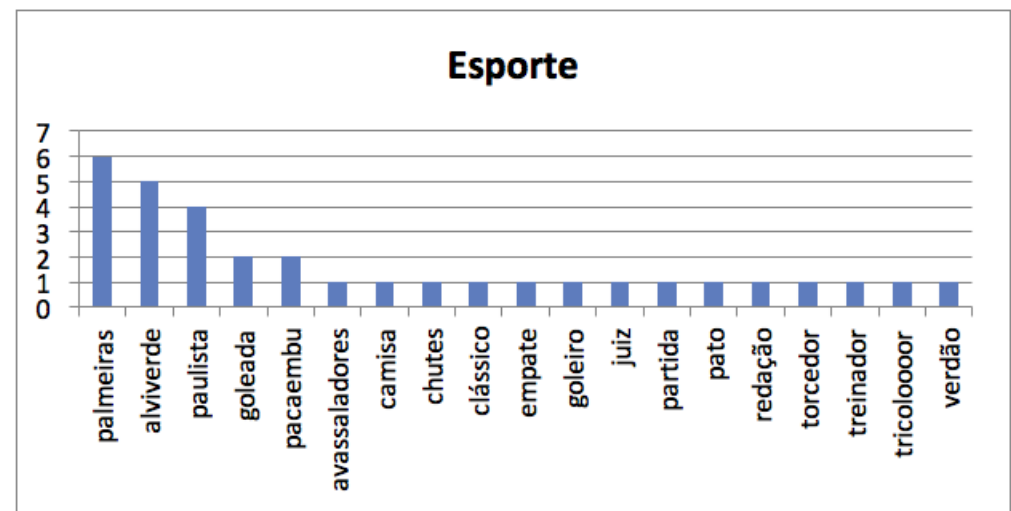

Fonte: Elaborado pela equipe da Rede Brasil Conectado

No supertema "evento" a palavra "festa" foi a única recorrente (2 repetições). As postagens mencionavam 3 eventos: convite para o harlem shake ${ }^{24}$ em uma casa noturna; um feriado cívico, devido à emancipação de um município e, ainda, um post sobre a

\footnotetext{
${ }^{24}$ Um dos hits da Internet: participantes dançam aleatoriamente e a gravação da dança em vídeo é postada. Shake significa se requebrar em inglês.
}

Comun. \& Inf., Goiânia, GO, v. 21, n. 1, p. 109-125, jan./mai. 2018 
comemoração ao "dia de São Patrício" (Saint Patrick’s Day), tradição irlandesa que inclui beber cerveja na celebração. Todos relacionados aos momentos de lazer dos jovens.

Gráfico 11 - Frequência de palavras no supertema evento

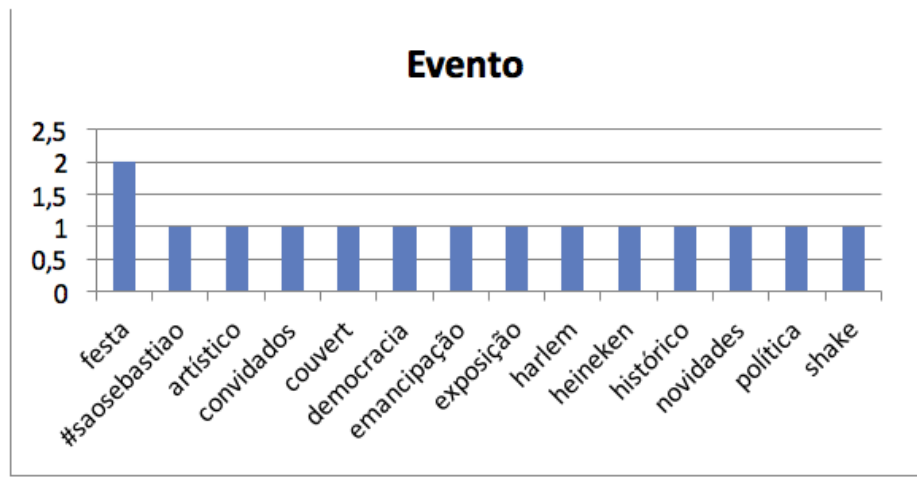

Fonte: Elaborado pela equipe da Rede Brasil Conectado

A análise das ocorrências desses últimos supertemas, do mesmo modo que em religiosidade-espiritualidade, evidenciam como as mediações culturais em seus consumos se manifestam nos usos midiáticos, sendo "futebol" um elemento geral da cultura nacional, sobretudo para o gênero masculino. Já "evento" demonstrou o tipo de repertório de produtos culturais consumidos por este jovens observados. A regularidade do estudo permitiria a configuração de um perfil de consumo cultural, apenas sugerido neste texto pelos limites do estudo exploratório.

\section{CONSIDERAÇÕES FINAIS}

Como escrevemos no início deste texto, a etapa exploratória da pesquisa aqui referenciada abrangeu a observação dos dados referentes aos "favoritos", item relevante para visualizar as preferências dos jovens na rede. Contudo, pela necessidade de síntese para esse artigo, apresentamos apenas os dados dos perfis e os supertemas, cuja análise conjunta nos mostrou que as trajetórias acadêmica, universitária e a atuação no mercado de trabalho foram destaque no dia a dia desses jovens, além de informações acerca de cursos, treinamentos, estágios e perspectivas de colocação profissional no futuro, ou seja, assuntos que refletiram as vivências e indefinições desse momento de vida.

$\mathrm{Na}$ análise dos 11 supertemas recorrentes, os mais citados foram "cotidiano, música, filosofia ordinária e humor", já "esportes e vida estudantil" tiveram menos adesão, apesar do interesse por jogos eletrônicos, aplicativos e esportes, com destaque para o futebol. 
Questões relativas aos universos local e regional permearam as timelines, indicando preocupação com o contexto em que estão diretamente inseridos. No caso do supertema "cotidiano", os jovens compartilharam mais os percalços do dia a dia e, em "filosofia ordinária", estiveram presentes menções à amizade, a deus e ao otimismo. Religiosidadeespiritualidade recebeu significativa adesão dos jovens, mas estava relacionada a um único assunto também presente na mídia à época ${ }^{25}$ : a sucessão do papa.

No supertema "música", a plataforma Youtube destacou-se como fonte preferencial de compartilhamento de gostos musicais e, do mesmo modo, o supertema "humor" ocupou um espaço significativo, com páginas do próprio Facebook compartilhadas. Os jovens paulistanos se interessaram também por notícias e questões ligadas aos direitos dos homossexuais e, de um modo geral, o Facebook se constituiu uma importante plataforma para a busca de notícias, divulgação de eventos e compartilhamento de informações.

Por fim, apesar dos limites deste estudo exploratório, consideramos possível extrair alguns pressupostos sobre as lógicas dos usos e consumos midiáticos do Facebook, a saber: uma função metamidiática, pela convergência entre mídias/plataformas e respectivas circulações de conteúdos da vida cultural, expressas como mediações comunicacionais das culturas dos jovens investigados, que criam mundos midiatizados. E ainda: a convergência entre mídias sugere novas manifestações da gramaticalidade da interação entre espaços midiáticos, a exemplo dos memes com músicas e de vídeos do Youtube, com suas distintas complexidades $^{26}$.

Outro pressuposto se estabelece na função mídia do $\mathrm{eu}$, que possibilita expressões individuais relacionadas, sobretudo, a elementos eufóricos da vida cotidiana, cujo imperativo do curtir é o lugar máximo de expressão dessa lógica. Acreditamos que o Facebook, como mediação comunicacional da cultura em suas funções metamídia e mídia do eu, apresenta um grande potencial sobre diferente recortes das mediações culturais como mediações comunicacionais das culturas. Isso permite indentificar algumas propriedades dos mundos midiatizados, compreendendo como a rede social participa na manutenção ou na transformação das culturas, na lógica das sociedades midiatizadas.

\section{REFERÊNCIAS}

\footnotetext{
${ }^{25}$ Disponível em: 〈https://glo.bo/2tdCBRJ>. Acesso em: 20 jun. 2017.

${ }^{26}$ Como escrevemos, uma observação mais longa e sempre a partir da coleta de dados brutos extraídos poderia oferecer perfis substanciosos da prática cultural comunicacional.
}

Comun. \& Inf., Goiânia, GO, v. 21, n. 1, p. 109-125, jan./mai. 2018 
HEPP, A. As configurações comunicativas de mundos midiatizados: pesquisa da midiatização na era da "mediação de tudo". Matrizes, v. 8, n. 1, p. 45-64, jan./jun. 2014. Disponível em: $<$ http://bit.ly/2tmetKR >. Acesso em: 20 jun. 2017.

JACKS, N. A.; TOALDO, M. et al. Brasil em números: dados para pesquisas de comunicação e cultura em contextos regionais. Florianópolis: Insular, 2014.

JENSEN, K. B. La semiótica social de la comunicación de masas. Barcelona: Bosch Editorial, 1997.

MARTÍN-BARBERO, J. Ofício de cartógrafo: travessias latino-americanas da comunicação na cultura. São Paulo: Loyola, 2004.

MARTÍN-BARBERO, J. Uma aventura epistemológica. Matrizes, v. 2, n. 2, p. 143-162, jan./jun. 2009. Disponível em: 〈http://bit.ly/2tdynJC>. Acesso em: 21 jun. 2017.

REDE BRASIL CONECTADO. Disponível em:

<https://redebrasilconectado.wordpress.com/>. Acesso em: 21 jun. 2017.

SILVESTRIN, C.; NOLL, G. (Org.) Capitais Brasileiras: dados históricos, demográficos, culturais e midiáticos. Curitiba: Appris, 2016.

TOALDO, M.; JACKS, N. Consumo midiático: uma especificidade do consumo cultural, uma antessala para os estudos de recepção. In: ENCONTRO ANUAL DA COMPÓS, 22., 2013, Bahia. Anais eletrônicos... Bahia: Universidade Federal da Bahia, 2013. Disponível em: $<$ http://bit.ly/2qNDAZ4 >. Acesso em: 20 jun. 2017.

TRINDADE, E.; PEREZ, C. Consumo Midiático e consumo midiatizado. In: LUVIZZOTO, C. K.; LOSNAK, C.J.; ROTHBERG, D. (Org.). Mídia e sociedade em transformação. São Paulo: Cultura Acadêmica, 2016. 